\title{
Eucalyptus ESTs involved in the production of 9-cis epoxycarotenoid dioxygenase, a regulatory enzyme of abscisic acid production
}

\author{
Iraê A. Guerrini $^{1 \#}$, Rodrigo M. Trigueiro ${ }^{1}$, Regina M. Leite ${ }^{1}$, Carlos F. Wilcken ${ }^{2}$, Edivaldo D. Velini ${ }^{2}$, \\ Edson S. Mori ${ }^{2}$, Edson L. Furtado ${ }^{2}$, Celso L. Marino ${ }^{3}$ and Ivan G. Maia ${ }^{3}$ \\ ${ }^{1}$ Universidade Estadual Paulista "Júlio de Mesquita Filho", Faculdade de Ciências Agronômicas, \\ Departamento de Recursos Naturais, Botucatu, SP, Brazil. \\ ${ }^{2}$ Universidade Estadual Paulista "Júlio de Mesquita Filho", Faculdade de Ciências Agronômicas, \\ Departamento de Produção Vegetal, Botucatu, SP, Brazil. \\ ${ }^{3}$ Universidade Estadual Paulista "Júlio de Mesquita Filho", Instituto de Biociências, \\ Departamento de Genética, Botucatu, SP, Brazil.
}

\begin{abstract}
Abscisic acid (ABA) regulates stress responses in plants, and genomic tools can help us to understand the mechanisms involved in that process. FAPESP, a Brazilian research foundation, in association with four private forestry companies, has established the FORESTs database (https://forests.esalq.usp.br). A search was carried out in the Eucalyptus expressed sequence tag database to find ESTs involved with 9-cis epoxycarotenoid dioxygenase (NCED), the regulatory enzyme for ABA biosynthesis, using the basic local BLAST alignment tool. We found four clusters (EGEZLV2206B11.g, EGJMWD2252H08.g, EGBFRT3107F10.g, and EGEQFB1200H10.g), which represent similar sequences of the gene that produces NCED. Data showed that the EGBFRT3107F10.g cluster was similar to the maize (Zea mays) NCED enzyme, while EGEZLV2206B11.g and EGJMWD2252H08.g clusters were similar to the avocado (Persea americana) NCED enzyme. All Eucalyptus clusters were expressed in several tissues, especially in flower buds, where ABA has a special participation during the floral development process.
\end{abstract}

Key words: Eucalyptus EST, abscisic acid, water deficit, drought resistance, NCED.

Received: May 31, 2004; Accepted: July 11, 2005.

Plant tolerance to drought involves several biochemical processes, whose understanding of is essential for the development of individuals with greater water stress withstanding capacity, thus enabling agricultural frontiers to be expanded into regions where water availability is a limiting factor.

The mechanisms of resistance to water deficit act separately or in combination. In general, these mechanisms involve physiological and morphological alterations that have a molecular/genetic basis. For this reason, genotypes differing in water deficit tolerance must present qualitative and quantitative differences in genic expression. A specific physiological response to water deficit represents, in reality, the combination of previous molecular events, which were activated by the perception of a stress signal. Understanding how these events are activated/inactivated and

Send correspondence to Iraê A. Guerrini. Universidade Estadua Paulista "Júlio de Mesquita Filho", Faculdade de Ciências Agronômicas, Departamento de Recursos Naturais/Ciência do Solo, Fazenda Experimental Lageado s/n, Caixa Postal 237, 18603-970 Botucatu, SP, Brazil. E-mail: iguerrini @ fca.unesp.br. \#Supported by CNPq how they interact among themselves is essential for the development of new varieties tolerant to drought periods (Nepomuceno et al., 2001).

One of the best-known mechanisms of tolerance to environmental stress is the production of Abscisic Acid (ABA). In higher plants, ABA plays important roles in embryo development and seed dormancy, in addition to being involved in plant adaptation to several stresses (drought, salinity, cold). When ABA is applied to plants, it causes the stomata to close quickly, thus reducing water loss by transpiration. In addition, water stress promotes a rapid increase in ABA content in the plants (Qin and Zeevaart, 1999). Evidence indicates that this increase in ABA is attributed to de novo synthesis (Zeevaart and Creelman, 1988).

Since the discovery of ABA in the beginning of the 60 s, a great deal of effort has been dedicated to understanding its biosynthesis. By means of genetic and biochemical studies, the biosynthesis pathway of ABA in higher plants is now understood in detail. Recently, all major genes that code for enzymes in the ABA biosynthesis pathway were 
identified (Schwartz et al., 2003). The new challenge is now to understand how these biosynthesis genes and the biosynthesis pathway are regulated as a whole (Xiong and Zhu, 2003).

In order to determine which step in ABA biosynthesis is stimulated by water stress, it is essential to first establish its biosynthesis pathway. $\mathrm{ABA}$ is a sesquiterpenoid $\left(\mathrm{C}_{15}\right)$, and two routes have been proposed for its biosynthesis. The first is the straight pathway from isopentenylpyrophosphate $\left(C_{5}\right)$, via farnesyl pyrophosphate $\left(C_{15}\right)$, into ABA. Current evidence indicates that this pathway operates in fungi (Zeevaart, 1999). And the second is the indirect pathway in which ABA is a product of carotenoid cleavage $\left(\mathrm{C}_{40}\right)$. This "indirect route" step remained unknown for many years due to the difficulty in promoting these reactions in vitro. With the identification and characterization of the ABAdeficient mutant gene, this problem was eventually solved.

Evidence indicates that this pathway works in green plants and was obtained with carotenoid-deficient mutants in research using marked ${ }^{18} \mathrm{O}_{2}$, where it was observed that in roots under water stress and in etiolated plant parts there was a 1:1 stoichiometric ratio between the disappearance of violaxanthin and neoxanthin and the formation of ABA and its catabolites, phaseic and dihydrophaseic acid (Zeevaart, 1999).

The direct proof of the pathway where ABA biosynthesis occurs by carotenoid cleavage came from the VP14 ABA-deficient corn mutant and its corresponding cloned VP14 gene (Tan et al., 1997). In enzyme assays, the recombinant VP14 protein cleaves 9-cis-epoxycarotenoid producing 2-cis,4-trans-xanthoxin and C25-apocarotenoid (Schwartz et al., 1997a). Due to the fact that no isomerization reaction occurs at the $\mathrm{C}_{15}$ precursor level, the precursor carotenoids must be in the 9-cis configuration, and converted into ABA, which is, by definition, 2-cis,4-trans (Qin and Zeevaart, 1999). Evidence indicates that the conversion of xanthoxin into ABA is not a limiting factor in ABA biosynthesis, and this last step in the pathway is not regulated by water deficit, since the carotenoid substrate is abundantly available in photosynthetic tissues (Parry et al.,1990). By elimination, 9-cis-epoxycarotenoid cleavage is the limiting step in the ABA biosynthesis pathway.

Qin and Zeevaart (1999) obtained a bean gene, PvNCED1, through cloning, which codes for the 9-cisepoxycarotenoid cleavage enzyme, and analyzed its enzymatic activity and location. Its water stress response was characterized in the form of mRNA and protein levels in leaves and roots. The results demonstrated that the cleavage reaction is the key step in abscisic acid biosynthesis regulation, and was induced by water stress.

The ABA-deficient mutants served as tools to reveal the ABA biosynthesis pathway. Because of early seed germination and the appearance of plant wilting, these faulty mutants were isolated from a number of plant species, in- cluding Zea mays, Lycopersicon esculentum, Nicotiana tabacum, Solanum tuberosum, Hordeum vulgare and Arabidopsis thaliana. Before the molecular identities of the affected genes were known, a principal ABA biosynthesis route was revealed by modeling ABA biosynthetic intermediate products in combination with nutritional assays involving those mutants. These studies suggested that ABA in higher plants is synthesized through an indirect pathway by cleavage of a $\mathrm{C}_{40}$ precursor carotenoid, followed by a two-step conversion of intermediate xanthoxin into ABA via ABA-aldehyde (Taylor et al., 2000; Finkelstein and Rock, 2002; Seo and Koshiba, 2002; Schwartz et al., 2003). So far, the main genes and enzymes from ABA-deficient mutants have been characterized in Arabidopsis (Schwartz et al., 2003). The Arabidopsis information can be applied to other plant species since the pathway and its respective genes are highly conserved in angiosperms (Xiong and Zhu, 2003).

The first specific step in the ABA biosynthesis pathway is the epoxidation of zeaxanthin and antheraxanthin into violaxanthin, which takes place within the plastids. This step is catalyzed by the enzyme zeaxanthin epoxidase (ZEP), which had its molecular identity first revealed in tobacco (Marin et al., 1996). After a series of structural modifications, violaxanthin is converted into 9-cis-epoxycarotenoid. The oxidative cleavage of the main 9-cisneoxanthin epoxycarotenoid by 9-cis epoxycarotenoid dioxygenase (NCED) generates an intermediate $C_{15}$ xanthoxin (Schwartz et al., 1997b). This was considered the first step in the ABA biosynthesis pathway. The xanthoxin product is then exported to the cytosol, where it is converted into ABA by a two-step reaction via ABA-aldehyde. A short-chain dehydrogenase/reductase (SDR) alcohol, coded by the AtABA2 gene (Rook et al., 2001; Cheng et al., 2002; González-Guzman et al., 2002), catalyzes the first step of this reaction and generates ABA-aldehyde. The ABAaldehyde oxidase enzyme (AAO) then catalyzes the last step in the biosynthesis pathway (Xiong and Zhu, 2003), as presented in Figure 1.

According to the research results obtained for ABA biosynthesis, it can be seen that the identification and isolation of genes involved in its production is extremely important, especially with respect to the gene that codes for the NCED enzyme, which is a step of the pathway whose efficiency could determine a higher or lower degree of plant resistance to environmental stresses. Based on this information, this work was aimed at identifying, in the FORESTs database, sequences that are homologous to the gene under consideration, already identified in other species.

Sequences representative of the NCED genes (involved in the production of abscisic acid) were selected from the NCBI (National Center for Biotechnology Information) or geneBank database. These peptide sequences were used in a search within the database generated by FORESTs (https:forest.esalq.usp.br), using the BLAST 


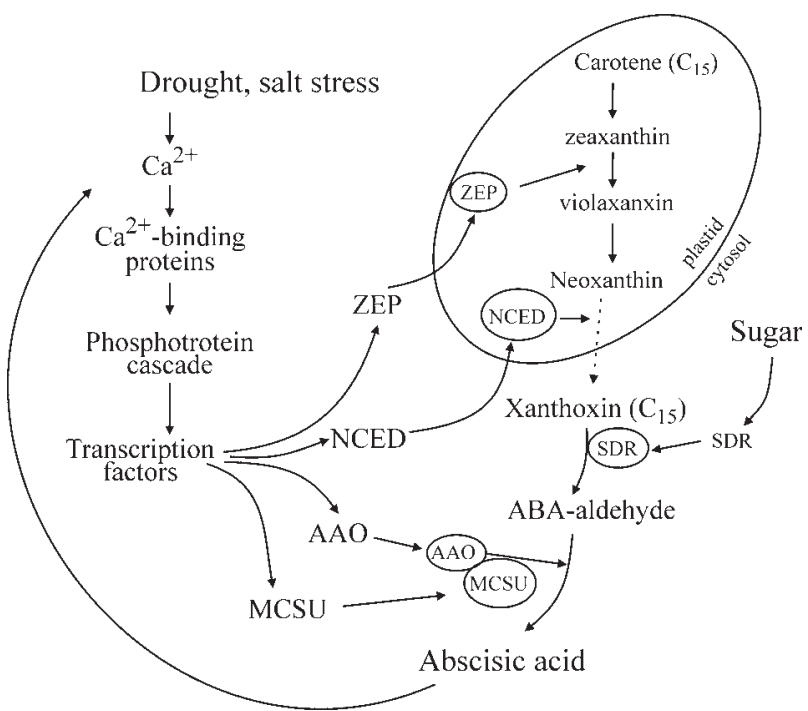

Figure 1 - ABA biosynthesis regulation. The NCED step (indicated by a dashed line) probably limits ABA biosynthesis in leaves. ZEP, zeaxanthin epoxidase; NCED, 9-cis epoxycarotenoid dioxygenase; AAO, ABA-aldehyde oxidase; MCSU, MoCo sulfurase; SDR, short-chain alcohol dehydrogenase/reductase. Adapted from Xiong and Zhu (2003).

tool (Altschud et al., 1990), where the probability value (e-value) was used to validate the sequences. The FORESTs database was formed consisting of 123,889 reads obtained from expressed sequence tags (ESTs) acquired from cDNA libraries of tissues from different organs of $E$. grandis, E. globulus, E. saligna, E. urophylla and E. camaldulensis. The libraries consisted of woods (WD), bark (BK), flower buds (FB), leaves (LV), seedlings (SL), stem (ST), root (RT), and callus (CL).

Four Eucalyptus clusters (EGEZLV2206B11.g, EGJ MWD2252H08.g, EGBFRT3107F10.g, EGEQFB1200H 10.g) found in the FORESTs database (Table 1) represent similar sequences to the sequence that codes for the gene responsible for producing the 9-cis epoxycarotenoid dioxygenase enzyme (NCED). This gene is extremely important in controlling the production of abscisic acid.

According to the dendrogram in Figure 2, generated from the amino acid sequences for the NCED enzyme of

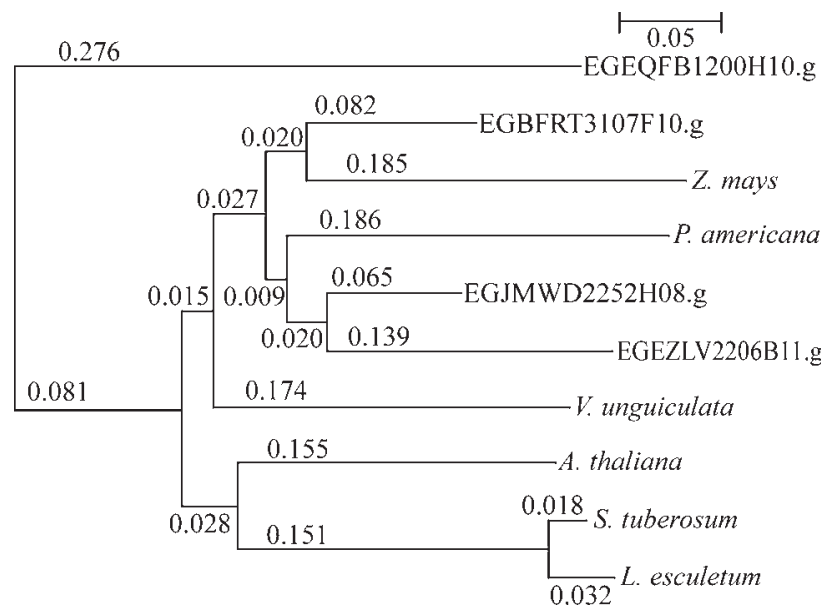

Figure 2 - Dendrogram showing the distance relations between the amino acid sequences of 9-cis-epoxycarotenoid dioxygenase for Eucalyptus clusters EGEZLV2206B11.g, EGJMWD2252H08.g, EGBFRT3107F10.g and EGEQFB1200H10.g, and the 9-cis-epoxycarotenoid dioxygenase of A. thaliana, L. esculetum, S. tuberosum, V. unguiculata, Z. mays and $P$. americana. The phylogenetic distance between sequences in the tree was calculated using the neighbor-joining algorithm.

different organisms and Eucalyptus clusters, it can be seen that the Eucalyptus cluster EGBFRT3107F10.g showed more similarity to the corn (Zea mays) NCED enzyme, while EGEZLV2206B11.g and EGJMWD2252H08.g clusters were similar to the avocado (Persea americana) NCED. Chernys and Zeevaart (2000) found that ABA biosynthesis in avocado is regulated at the level of carotenoid cleavage, which is catalyzed by NCED.

The abscisic acid biosynthesis occurs in fruits, seeds, roots, leaves and branches, even though its synthesis is widely distributed throughout the plant. The highest production of that hormone, as a response to drought, occurs in leaves, followed by a small production in branches and roots, while fruits do not change their ABA contents as a drought response (Coll et al., 1992). This situation can be observed in the sources of reads that made up the clusters under consideration. The EGEZLV2206B11.g cluster is from only two types of tissues, leaves (LV) and stem (ST),

Table 1 - Similar clusters to the NCDE gene, found in the FORESTs database.

\begin{tabular}{|c|c|c|c|c|c|c|c|c|c|c|}
\hline \multirow[t]{3}{*}{ Organism } & \multirow{3}{*}{$\begin{array}{l}\text { Accession } \\
\text { number }\end{array}$} & \multirow[t]{3}{*}{ GI } & \multicolumn{8}{|c|}{ Eucalyptus cluster } \\
\hline & & & \multicolumn{2}{|c|}{ EGEZLV2206B11.g } & \multicolumn{2}{|c|}{ EGJMWD2252H08.g } & \multicolumn{2}{|c|}{ EGBFRT3107F10.g } & \multicolumn{2}{|c|}{ EGEQFB1200H10.g } \\
\hline & & & E-value & Ident. & E-value & Ident. & E-value & Ident. & E-value & Ident. \\
\hline Phaseolus vulgaris & AAF26356 & 6715257 & 0.0 & $78 \%$ & e-131 & $80 \%$ & $5 e-94$ & $74 \%$ & $4 e-90$ & $36 \%$ \\
\hline Arabidopsis thaliana & NM_117945 & 18415070 & 0.0 & $58 \%$ & $3 e-99$ & $63 \%$ & $3 e-83$ & $71 \%$ & $4 e-76$ & $35 \%$ \\
\hline Lycopersicon esculentum & AJ439079 & 28974076 & 0.0 & $70 \%$ & e-131 & $77 \%$ & $2 \mathrm{e}-98$ & $38 \%$ & $3 e-94$ & $75 \%$ \\
\hline Persea americana & AF224672 & 12655868 & 0.0 & $72 \%$ & e-114 & $69 \%$ & $8 \mathrm{e}-88$ & $69 \%$ & $3 e-84$ & $36 \%$ \\
\hline Vigna unguiculata & AB030293 & 9857289 & 0.0 & $69 \%$ & e-132 & $80 \%$ & $2 \mathrm{e}-93$ & $74 \%$ & $1 \mathrm{e}-89$ & $36 \%$ \\
\hline Solanum tuberosum & $\mathrm{AJ} 276244$ & 7209268 & 0.0 & $69 \%$ & e-133 & $78 \%$ & $1 \mathrm{e}-96$ & $39 \%$ & $2 \mathrm{e}-94$ & $74 \%$ \\
\hline Zea mays & U95953 & 2232016 & 0.0 & $69 \%$ & e-133 & $68 \%$ & $2 \mathrm{e}-97$ & $40 \%$ & $3 e-90$ & $72 \%$ \\
\hline
\end{tabular}


and the highest number of reads came from stem tissues. The EGJMWD2252H08.g and EGBFRT3107F10.g clusters are from only one type of tissue, wood (WD) and root (RT), respectively. The EGEQFB1200H10.g cluster presents cDNAs from different tissues of plants, but showed a higher number of reads from flower bud tissues (FB) and leaves (LV3). The NCED gene expression in flower buds is expected due to special participation of ABA during the floral development process, as observed by Tan et al. (2003) in studies with AtNCED genes in Arabidopsis thaliana. These studies indicate that the developmental control of ABA synthesis involves localized patterns of AtNCED gene expression.

\section{Acknowledgements}

We would like to thank Ripasa S.A. Celulose e Papel, Duratex S.A., Votorantim Celulose e Papel and Cia. Suzano/Bahia Sul de Papel e Celulose. This work was supported by FAPESP (Fundação de Amparo a Pesquisa do Estado de São Paulo).

\section{References}

Altschul SF, Madden TL, Schaaffer AA, Zhang J, Zhang Z, Miller W and Lipman DJ (1990) Gapped BLAST and PSI-BLAST: A new generation of protein database search programs. Nucleics Acids Res 25:3389-3402.

Cheng WH, Endo A, Zhou L, Penney J, Chen HC, Arroyo A, Leon P, Nambara E, Asami T, Seo M, Koshiba T, Sheen J (2002) A unique short-chain dehydrogenase/ reductase in Arabidopsis glucose signaling and abscisic acid biosynthesis and functions. Plant Cell 14:2723-2743.

Chernys JT and Zeevaart AD (2000) Characterization of the 9-cis-epoxycarotenoid dioxygenase gene family and the regulation of abscisic acid biosynthesis in avocado. Plant Physiol 124:343-353.

Coll JB, Rodrigo GN, Garcia BS and Tamés RS (1992) Ácido abscísico y otros inhibidores. In: Fisiología Vegetal. 6th ed. Ediciones Pirámide, Madrid, pp 416-431.

Eucalyptus Genome Sequencing Project Consortium (FORESTs): https://forests.esalq.usp.br.

Finkelstein RR and Rock CD (2002) Abscisic acid biosynthesis and response. In: Somerville CR and Meyerowitz EM (eds) The Arabidopsis Book. American Society of Plant Biologists, Rockville, pp 1-52.

González-Guzmán M, Apostolova N, Bellés JM, Barrero JM, Piqueras P, Ponce MR, Micol JL, Serrano R and Rodríguez PL (2002) The short-chain alcohol dehydrogenase ABA2 catalyzes the conversion of xanthoxin to abscisic aldehyde. Plant Cell 14:1833-1846.

Marin E, Nussaume L, Quesada A, Gonneau M, Sotta B, Hugueney P, Frey A and Marion-Poll A (1996) Molecular identification of zeaxanthin epoxidase of Nicotiana plumbaginifolia, a gene involved in abscisic acid biosynthesis and corresponding to the ABA locus of Arabidopsis thaliana. EMBO J 15:2331-2342.

Nepomuceno AL, Neumaier N, Farias JRB and Oya, T (2001) Tolerância à seca em plantas. Biotecnolog. Cienc Desenvolv 23:12-18.

Parry AD, Babiano MJ and Horgan R (1990) The role of cis-carotenoids in abscisic acid biosynthesis. Planta 182:118-128.

Qin X and Zeevaart JAD (1999) The 9-cis-epoxycarotenoid cleavage reaction is the key regulatory step of abscisic acid biosynthesis in water-stressed bean. Proc Natl Acad Sci USA 96:15354-15361.

Rook F, Corke F, Card R, Munz G, Smith C and Bevan MW (2001) Impaired sucrose-induction mutants reveal the modulation of sugar-induced starch biosynthetic gene expression by abscisic acid signalling. Plant J 26:421-433.

Schwartz SH, Tan BC, Gage DA, Zeevaart JAD and Mccarty DR (1997a) Specific oxidative cleavage of carotenoids by VP14 of maize. Science 276:1872-1874.

Schwartz SH, Léon-Kloosterziel KM, Koornneef M and Zeevaart JAD (1997b) Biochemical characterization of the $a b a 2$ and aba3 mutants in Arabidopsis thaliana. Plant Physiol 114:161-166.

Schwartz SH, Qin X and Zeevaart JAD (2003) Elucidation of the indirect pathway of abscisic acid biosynthesis by mutants, genes, and enzymes. Plant Physiol 131:1591-1601.

Seo M and Koshiba T (2002) Complex regulation of ABA biosynthesis in plants. Trends Plant Sci 7:41-48.

Tan BC, Schwartz SH, Zeevaart JAD and Mccarty DR (1997) Genetic control of abscisic acid biosynthesis in maize. Proc Natl Acad Sci USA 94:12235-12240.

Tan BC, Joseph LM, Deng WT, Liu L, Li QB, Cline K and Mc Carty DR (2003) Molecular characterization of the Arabidopsis 9-cis-epoxycarotenoid dioxygenase gene family. Plant J 35:44-56.

Taylor IB, Burbidge A and Thompson AJ (2000) Control of abscisic acid synthesis. J Exp Bot 51:1563-1574.

Xiong L and Zhu JK (2003) Regulation of abcisic acid biosynthesis. Plant Physiol 133:29-36.

Zeevaart JAD (1999) Abscisic acid metabolism and its regulation. In: Hooykaas PJJ, Hall MA and Libbenga KR (eds) Biochemistry and Molecular Biology of Plant Hormones. Elsevier Science, Amsterdam, pp 189-207.

Zeevaart JAD and Creelman RA (1988) Metabolism and physiology of abscisic acid. Annu Rev Plant Physiol Plant Mol Biol 39:439-473.

Associate Editor: Helaine Carrer 